NBER WORKING PAPER SERIES

\title{
ESTIMATION AND IDENTIFICATION OF MERGER EFFECTS: AN APPLICATION TO HOSPITAL MERGERS
}

\author{
Leemore S. Dafny \\ Working Paper 11673 \\ http://www.nber.org/papers/w11673
NATIONAL BUREAU OF ECONOMIC RESEARCH
1050 Massachusetts Avenue
Cambridge, MA 02138
October 2005

I am grateful for helpful suggestions by an anonymous referee, Julie Cullen, David Dranove, Jon Gruber, Vivian Ho, Richard Lindrooth, Michael Mazzeo, Robert Town, and especially Julian Jamison, Ilyana Kuziemko, and Scott Stern. This paper has also benefited from comments by numerous colleagues at seminars and conferences. I thank David Dranove, Richard Lindrooth, and Laurence Baker for generously sharing their data, and Jean Roth of NBER for assistance with the HCRIS database. Angela Malakhov, Fiona Wong and Subramaniam Ramanarayanan provided excellent research assistance. Support from the Institute for Policy Research at Northwestern is gratefully acknowledged. The views expressed herein are those of the author(s) and do not necessarily reflect the views of the National Bureau of Economic Research.

(C) 2005 by Leemore S. Dafny. All rights reserved. Short sections of text, not to exceed two paragraphs, may be quoted without explicit permission provided that full credit, including $\odot$ notice, is given to the source. 
Estimation and Identification of Merger Effects: An Application to Hospital Mergers

Leemore S. Dafny

NBER Working Paper No. 11673

October 2005, Revised October 2007

JEL No. I1,D4,L0

\begin{abstract}
$\underline{\text { ABSTRACT }}$
Advances in structural demand estimation have substantially improved economists' ability to forecast the impact of mergers. However, these models rely on extensive assumptions about consumer choice and firm objectives, and ultimately observational methods are needed to test their validity. Observational studies, in turn, suffer from selection problems arising from the fact that merging entities differ from non-merging entities in unobserved ways. To obtain an accurate estimate of the effect of consummated mergers, I propose a combination of rival analysis and instrumental variables. By focusing on the effect of a merger on the behavior of rival firms, and instrumenting for these mergers, unbiased estimates of the effect of a merger on market outcomes can be obtained. Using this methodology, I evaluate the impact of independent hospital mergers between 1989 and 1996 on rivals' prices. I find sharp increases in rivals' prices following a merger, with the greatest effect on the closest rivals. The results for this industry are more consistent with predictions from structural models than with prior observational estimates.
\end{abstract}

Leemore S. Dafny

Department of Management and Strategy

Kellogg School of Management

Northwestern University

2001 Sheridan Road

Evanston, IL 60208-2001

and NBER

1-dafny@kellogg.northwestern.edu 


\section{Introduction}

In recent years, economists have taken advantage of methodological advances in the estimation of structural demand models to simulate the impact of horizontal mergers. The strengths of this approach are many, not least the ability to predict the impact of future mergers rather than extrapolate from the experience of mergers that have already occurred. However, these models require extensive assumptions about consumer demand and firm objectives, do not fully incorporate rivals' reactions to actions taken by merging parties, and are computationally intensive and challenging to implement. Moreover, the predictions generated by such models can only be validated by analyzing the effects of consummated mergers. To date, the courts have also been more receptive to observational methods that provide "hard evidence" of the likely impact of merger, as in the Staples-Office Depot case. ${ }^{1}$

Unfortunately, most observational or "reduced-form" analyses of the impact of mergers fail to address fundamental selection problems arising from the fact that merger events are not randomly assigned. These studies typically compare outcomes of merging firms with those of non-merging firms. The resulting estimates suffer from a classical selection problem, as merging firms are likely different from non-merging firms in unobserved ways that affect the outcomes of interest. For example, suppose that financially-distressed firms are more likely to be party to a merger, and post-merger the new entities reduce costs and decrease prices. Conditional on survival, these firms might

\footnotetext{
${ }^{1}$ In its successful attempt to block this merger, the FTC presented evidence that office supply prices were lowest in markets where all three office supply superstores competed (Staples, Office Depot, and Office Max). Prices were higher in markets with two competitors, and higher still in markets with a single office supply superstore. Federal Trade Commission v. Staples, Inc. and Office Depot, Inc., 1997.
} 
have reduced costs and decreased prices even more absent a merger. More generally, any omitted factor that is correlated with the outcome measure as well as with the probability of merger will generate biased estimates of the impact of merger.

Some studies enhance the basic differences-in-differences approach by using matching algorithms to identify a superior control group (e.g. Dranove and Lindrooth 2003). Yet another approach, introduced by Eckbo (1983), is to eliminate the merging entities from the analysis entirely and to focus on the responses of rivals to mergers. If merging parties exercise their newly-acquired market power by raising price, ceteris paribus their rivals will be able to raise price as well. ${ }^{2}$ Thus, rival analysis compares the outcomes of firms with merging rivals to the outcomes of firms without merging rivals. These results are also likely to be biased by selection, however, as firms with merging rivals are likely different from firms without merging rivals.

This paper improves upon prior observational studies by combining rival analysis with instrumental variables (IV). I estimate the effect of a rival's merger on a firm's own price, instrumenting for whether a firm is exposed to a rival's merger. Provided this instrument is correlated with the probability of rival merger and uncorrelated with other unobserved factors affecting a firm's own price, this methodology will generate unbiased estimates of the causal effect of merger on market-level outcomes. I test this approach using data on the general acute-care hospital industry in the U.S., a sector that experienced a wave of merger activity during the 1990s.

\footnotetext{
${ }^{2}$ This argument assumes prices are strategic complements. Hospitals are typically modeled as differentiated Bertrand competitors, hence the assumption. See Gaynor and Vogt (2003) for an excellent discussion of prior theoretical and empirical work. Rival analysis has also been used to infer the competitive effects of other decisions, such as changes in capital structure (Chevalier 1995).
} 
The instrument I propose for merger in the hospital industry is co-location. Using the exact latitude and longitude coordinates for each hospital's main address in 1988, I identify co-located or adjacent hospitals, defined as hospitals within 0.3 miles of each other "as the crow files" and no more than 5 blocks apart. Using this criterion, 191 (3.6 percent) of the 5,373 general, non-federal hospitals in the non-territorial U.S. in 1988 were co-located with at least one other hospital. There are two reasons such hospitals should be more likely to merge: the potential to cut costs through the elimination of duplicate departments is greater, and the ability to increase price is greater because location is a primary differentiating factor for inpatient care (Dranove and White 1994, Tay 2003). This prediction is borne out in the data, which shows that co-located hospitals are nearly three times as likely to merge as non-co-located hospitals, a factor that is scarcely diminished after controlling for a large set of hospital and market characteristics. Thus, rival co-location is an excellent instrument for rival merger. In this study, a rival is defined as another hospital located within a certain distance from the hospital in question, e.g. 7 miles.

Using this instrument together with data on hospital mergers occurring between 1989 and 1996, I find evidence of substantial post-merger price increases by rivals of merging hospitals. These increases were realized by 1997; prices appear to stabilize thereafter. Price increases were greater among hospitals that were geographically closer to the merging parties. Failing to instrument for rivals' mergers produces a statistically insignificant estimate of less than 2 percent. 
The findings caution against analyses that compare merging and non-merging firms, particularly in the same market, where reactions to rivals' prices are likely. The estimates presented here are far more consistent with predictions from structural models of demand in similar settings (Capps, Dranove and Satterthwaite (2003); Gaynor and Vogt (2003)) than with estimates from prior observational studies (e.g. Connor et al. 1998), which generally find no effect or a negative effect of merger on price. This finding supports the use of structural models for prospective merger analysis. Finally, the results suggest that hospital markets are far smaller than those typically adopted by researchers, practitioners, and courts.

The paper proceeds as follows. Section 2 lays the theoretical foundation for the empirical analysis. Section 3 describes the hospital industry and summarizes prior related research. Section 4 defines the study samples and provides descriptive statistics. Section 5 presents the empirical specifications and results. Section 6 explores the sensitivity of the results to alternative specifications. Section 7 concludes.

\section{Theoretical Framework}

The theoretical foundation for my empirical strategy is a simple model of spatial differentiation, Salop's Circular City (1979). Firms independently maximize their profits taking others' actions as given; differentiation among the firms produces equilibrium prices that exceed costs. In Salop's model, the location of N firms along a circle of unit circumference is exogenously determined. Consumers of mass 1 are uniformly

\footnotetext{
${ }^{4}$ Colocated hospitals are by definition undifferentiated, so under common ownership the price would be the same regardless of the number of hospitals that remain open at the site.
} 
distributed along the circle, and have unitary demand and value $v$ for the product, regardless of the firm supplying it. When purchasing this product from firm $j$, consumer $i$ incurs transport costs of $t^{*} d_{i j}$, where $d_{i j}$ denotes the distance (along the circle) between $i$ and $j$. Transport costs can be viewed more generally as the costs associated with consuming a product that differs from the consumer's optimal product (i.e. a product that coincides with her location in product space). To illustrate the effect of a merger in this setting, and particularly a merger of co-located firms, I solve Salop models that reflect the market structures I use to identify merger effects.

Gal-Or (1999) also uses the Salop circle to model competition in this sector, with separate circles for hospitals and insurers in a given geographic market. Gal-Or's treatment focuses on when it is optimal to merge without closing a facility post-merger, and on how this decision is influenced by the interaction between the market structures of the hospital and insurance sectors. The closure decision is a non-issue in the present setting, where the mergers of interest occur between co-located hospitals. ${ }^{4} \mathrm{I}$ do not model the interaction between hospitals and insurers; this interaction clearly influences the realized prices, however, in the empirical analyses.

Consider two circular cities with 3 firms each, denoted H, R1, and R2 (representing the hospital of interest, rival 1, and rival 2). In market 1 , the rivals are located in exactly the same spot and $\mathrm{H}$ is as far away as possible. In market 2, the three firms are distributed evenly around the circle. These configurations are illustrated in Figure 1 below. 
Figure 1. Illustration of Two Hypothetical Markets

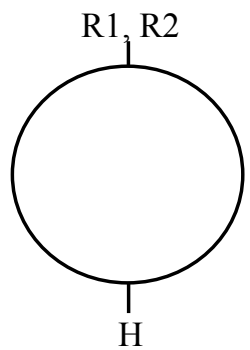

Market 1

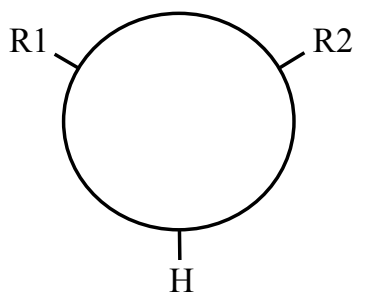

Market 2

I conjecture that R1 and R2 in market 1 are likelier to merge than R1 and R2 in market 2. If true, and if firm location is exogenous, $\mathrm{H}$ is exogenously more likely to be exposed to a rival merger. Under these assumptions (explored in subsequent sections), the number of co-located rival pairs a hospital has can serve as an instrument for rival merger. The outcome I consider in this study is price.

To illustrate the effect on H's price of a merger between co-located rivals, I derive the pre and post-merger equilibrium prices in market 1. For the sake of comparison, I derive the same for market 2, assuming one of the $\mathrm{R}$ facilities closes post-merger and the other remains in the same location. ${ }^{5}$ Without loss of generality, I set the marginal cost of each firm equal to zero. Appendix 1 gives the objective functions and equilibrium prices for each firm-type ( $\mathrm{R}$ and $\mathrm{H}$ ) in each market (1 and 2) and scenario (pre and post-merger of R1 and R2). Here I describe the general results.

So long as $t$ is not so high that hospital $\mathrm{H}$ enjoys a local monopoly and is unaffected by the actions of its rivals, a merger of co-located rivals will result in a very

\footnotetext{
${ }^{5}$ This seems the most plausible scenario given the high costs of construction and chronic overcapacity in the industry during the merger wave.
} 
sizeable price increase (up to 100 percent). ${ }^{6}$ The price increase following a merger of non-co-located rivals (as in market 2) is relatively smaller. The reason is that R1 and R2 compete more intensely before the merger in market 1 . They are undifferentiated and therefore set their prices equal to cost. When they merge, market prices increase dramatically. In market 2, R1 and R2 are differentiated competitors pricing above cost prior to the merger, so the merger has a smaller impact on optimal post-merger pricing.

In Section 6, "Extensions and Robustness," I return to these models to investigate the theoretical validity of the identifying assumption for the instrumental variables-rival analysis: that during the merger wave, price growth in the two market types (conditional on observables) would have been the same but for the increased frequency of mergers in markets with co-located rivals. (Note I need not assume that pre-merger price levels of the two market types are the same; indeed, the solutions presented in Appendix 1 illustrate they are not.) Both the theoretical results and the empirical tests presented below suggest colocation is not associated with faster price growth except through its effect on the propensity to merge.

The following section describes the U.S. hospital industry during the 1980s and 1990s, and discusses prior estimates of the effects of mergers in this sector.

\footnotetext{
${ }^{6}$ The markets I consider are sufficiently small and contain a large enough number of providers to rule out monopolistic behavior.
} 


\section{Background}

Until 1984, U.S. hospitals were generally reimbursed on a cost-plus basis by public and private insurers. In an effort to control escalating costs, the Medicare program instituted the Prospective Payment System (PPS) in 1984. Under PPS, hospitals receive a fixed payment for each Medicare patient in a given diagnosis-related group (DRG), making hospitals the residual claimants of any profits or losses. Payments were generous during the first few years of PPS, but by 1989 the majority of hospitals were earning negative margins on Medicare admissions (Coulam and Gaumer 1991). These financial pressures were exacerbated by the rise of managed care in the private sector. Managed care penetration increased from under 30 percent of private insurance in 1988 to nearly 95 percent by 1999 (Kaiser Family Foundation 2004), bringing about a shift from fee-forservice to negotiated prices. Thus, the motives to consolidate intensified substantially during the 1990s, triggering an unprecedented wave of mergers, acquisitions, and closures. Between 1989 and 1996, there were 190 hospital mergers, as compared to 74 during 1983-1988 (Bazzoli et al, 2002). ${ }^{7}$ As a result, recent studies of hospital mergers have focused on this time period (e.g. Bazzoli et al. 2002, Dranove and Lindrooth 2003).

Hospital mergers have received a great deal of attention from healthcare economists and antitrust enforcement agencies, in part because of the volume of patients and revenues involved. In 2001, the 5,801 hospitals in the U.S. treated 1.68 million outpatients and 658,000 inpatients each day, collecting $\$ 451$ billion in revenues. By

\footnotetext{
${ }^{7}$ These merger counts refer to legal consolidations of two or more hospitals under single ownership, and were verified by the American Hospital Association for 1983-1988, and Bazzoli et al. for 1989-1996.
} 
comparison, expenditures on new passenger vehicles in 2001 totaled $\$ 106$ billion. $^{8}$ The localized nature of competition is also a source of concern for antitrust enforcement agencies, as monopoly and oligopoly providers in a given geographic area can sustain supracompetitive prices.

The not-for-profit status of most hospitals, however, presents the possibility that hospitals will not exploit post-merger increases in market power. This is an argument the courts have often cited in rejecting attempts to block proposed hospital mergers. ${ }^{9}$ Since 1991, the Department of Justice and Federal Trade Commission have tried to enjoin 7 hospital mergers and failed to prevail a single time. ${ }^{10}$ After a long hiatus, the FTC changed course and began performing retrospective analyses of consummated mergers to identify possible anticompetitive conduct. This initiative was dealt a severe blow in 2007 when the full Commission failed to uphold an order to divest issued by an administrative judge against not-for-profit Evanston Northwestern Healthcare Corporation. $^{11}$

\footnotetext{
${ }^{8}$ U.S. Statistical Abstract (2003), Tables 158, 170, and 667.

${ }^{9}$ There are at least two distinct arguments espoused in these court rulings. In Long Island Jewish Medical Center, the court cited the "genuine commitment" of the merging hospitals "to help their communities." In Butterworth Health Corporation, the court was convinced that the merging hospitals would not raise prices "[b]ecause the boards are comprised of community and business leaders whose companies pay the health care costs of their local employees." (Improving Health Care: A Dose of Competition, A Report by the Federal Trade Commission and the Department of Justice, Ch. 4 p. 30)

${ }^{10}$ FTC Antitrust Actions in Health Care Services and Products, Washington, DC, October 2003, and Town and Vogt (2005).

${ }^{11}$ The complaint against Evanston Northwestern Healthcare Corporation (ENH) alleged that ENH increased price "far above price increases of other comparable hospitals" after acquiring nearby Highland Park Hospital in 2000 (Evanston Northwestern Healthcare Corporation and ENH Medical Group, Inc., File No. 011 0234, Docket No. 9315, February 2004). In October 2005, Chief Administrative Law Judge Stephen J. McGuire ruled in favor of the FTC and ordered ENH to divest Highland Park Hospital. This order was stricken upon appeal to the full Commission in August 2007. The opinion concurred with the finding of anticompetitive conduct, but called the divestiture order "unwarranted." (Opinion of The Commission, Docket No. 9315, August 6, 2007)
} 
Despite the sustained interest in hospital mergers, including private lawsuits challenging post-merger price increases, economists have failed to reach a consensus on the price effects of mergers in this sector. Gaynor and Vogt (2000), Connor and Feldman (1998), and Dranove and Lindrooth (2001) provide excellent summaries of the extensive literature on hospital competition and mergers. Most relevant for the present work are longitudinal studies that compare pre and post-merger outcomes. The majority of these studies focus on the cost reductions achieved by merging institutions because hospitals typically cite economies of scale and increased purchasing power as the main motives for merger. These studies have generally found very modest impacts of merger on costs, with two recent exceptions, Alexander (1996) and Dranove and Lindrooth (2003). Using data on mergers of previously independent hospitals that operate under a single license post-merger, Dranove and Lindrooth find post-merger cost decreases of 14 percent. These are precisely the mergers I use for my analysis. The combination of large postmerger price increases (implied by my results) and cost decreases suggests sizeable profit gains for merging hospitals.

The pre vs. post pricing studies are fewer in number and generally find price reductions following merger (e.g. Connor, Feldman, and Dowd 1998; Spang, Bazzoli, and Arnould 2001). These estimates are plagued by the selection problems described earlier, and biased downward by the use of nonmerging hospitals as control groups. If nonmerging rivals raise their prices in response to price increases by merging parties, mergers could be associated with no relative price increase for merging parties in a given market area but a large absolute price increase for the market area as a whole. 
Krishnan (2001) addresses the selection problem by comparing price growth for diagnoses in which merging hospitals gained substantial market power $(>20 \%)$ with price growth for diagnoses in which they gained insignificant share $(<5 \%)$. Using data on 11 hospital mergers in Ohio in 1994 and 1995, Krishnan finds that merging hospitals increased price 8.8 percent more in diagnoses where they gained substantial market share. By design, this estimate is downward-biased: it eliminates hospital-wide price increases, which are likely because many hospital features (e.g. location) are constant across services. In examining hospital responses to diagnosis-specific price changes imposed by Medicare, Dafny (2005) finds little evidence that hospitals compete in quality at the diagnosis level; rather, the data are consistent with competition in overall hospital quality. These results suggest the downward bias in Krishnan's estimates may be substantial.

Two prior studies use rival analysis to estimate the impact of merger on average market price. Woolley (1989) is a classic "event study" that traces the effect of 29 merger-related events from 1969-85 on the stock prices of rival hospital chains. The study finds a positive relationship between pro-merger events and stock price, but has been criticized on methodological grounds due to the events selected, the definition of rival chains, and the fact that only a small fraction of hospitals are owned by publiclytraded firms (Vita and Schumann 1991). Connor and Feldman (1998) compare price and cost growth between 1986 and 1994 for non-merging hospitals with merging rivals (hereafter NMW hospitals) and non-merging hospitals without merging rivals (hereafter NMWO hospitals). They find no effect of rival mergers on price, with the exception of mergers with an intermediate level of post-merger market share, where a small effect (3 percent over 8 years) is found. The lack of an effect for larger mergers is attributed to the 
ability of the newly-formed hospitals to dominate the market and suppress rivals' prices through merger-related quality improvements.

My analysis also focuses on price changes of non-merging hospitals over a long period of time (1988-1997) and across all states. However, I take steps to examine and address the selection problem that persists in rival analyses of mergers. First, I apply sample restrictions that substantially reduce the differences in observable characteristics of NMW and NMWO hospitals. Second, I introduce rival colocation as an instrument for rival merger. These steps are discussed in turn in section 4 (Data) and 5 (Empirical Analysis).

\section{$4 \quad$ Data}

Merger data constructed for Dranove and Lindrooth (2003) was generously provided by the authors. Using the Annual Survey of Hospitals and the Annual Guide to Hospitals, both produced by the American Hospital Association (AHA), Dranove and Lindrooth identified 97 independent hospital mergers between 1989 and 1996. They define an independent merger as a combination of two hospitals that are not affiliated with any hospital "system" into a single entity. To qualify as a merger in this dataset, the newlycreated hospital must report a single set of financial and utilization statistics and surrender one of their facility licenses. Figure 2 graphs the distribution of these mergers over time. ${ }^{13}$ Because my instrument only predicts the incidence and not the timing of

\footnotetext{
${ }^{13}$ Although Dranove and Lindrooth's data ends in 1996, merger figures reported by Cuellar and Gertler (2003) for 1994-2000 reveal a steep dropoff in merger activity in 1997, and a steady decline thereafter.
} 
merger (i.e. the instrument is not time-varying), I cannot exploit merger dates in my analysis. I therefore create an indicator variable for merger between 1989 and 1996, using the sample of general, non-federal hospitals present in the 1988 AHA Survey and located in metropolitan statistical areas or counties with more than 100,000 residents. ${ }^{14}$ (I exclude these hospitals because Dranove and Lindrooth did not consider mergers in rural areas.) The AHA survey provides descriptive data for each hospital, including location, ownership status, and number of beds. Note that while independent mergers were more common during the latter part of the study period, those involving co-located hospitals (the subset that provides the variation exploited in the IV analysis), are fairly evenly distributed over time. ${ }^{15}$

For each hospital in the sample, I obtain panel data on financial measures from the Healthcare Cost Reporting Information System (HCRIS), a database maintained by the Centers for Medicare and Medicaid Services (CMS). HCRIS contains annual financial and utilization data for all providers receiving reimbursement from either program under CMS' purview. Over 99 percent of the hospitals in my sample appear in HCRIS, which can be purchased from CMS for a nominal fee.

Average hospital price in a given year is calculated as inpatient revenue per casemix adjusted discharge. ${ }^{16}$ Other researchers have used similar measures, e.g. inpatient

\footnotetext{
${ }^{14}$ Of the 5,373 general, non-federal hospitals located in the mainland U.S. in 1988, 466 are dropped due to these restrictions.

${ }^{15}$ There are 10 mergers involving colocated hospitals during the study period; 9 of these are cases in which two colocated hospitals merged with each other.

${ }^{16}$ More precisely, price $=[$ hospital inpatient routine service charges + hospital intensive care charges + hospital inpatient ancillary charges)*discount factor - Medicare primary payor amounts - Medicare total amount payable $] /[$ (total discharges excluding swing/SNF - total Medicare discharges excluding swing/SNF)*case-mix index]. The discount factor is defined as 1- (contractual discounts/total patient charges), and reflects the common practice of discounts for private insurers. The above formula was
} 
revenue per discharge (Connor and Feldman 1998) or inpatient revenue per diem, controlling for patient diagnosis (Keeler et al. 1999). ${ }^{17}$ In calculating price, I exclude Medicare revenues and discharges because the federal government sets prices for these patients. However, I use each hospital's case-mix index (CMI) for Medicare patients as a proxy for the non-Medicare CMI, which is not reported. Medicare CMIs are obtained from the Prospective Payment Impact Files produced annually by CMS. ${ }^{18}$ The variables needed to calculate price are available for FY1985-2000, which spans the period 3 years before the first merger in the data to three years after the last merger in the data.

To reduce the influence of coding errors, observations in the 5-percent tails of price in a given year are assigned a missing value for that year. ${ }^{20}$ The dependent variables are the change in log price for a given hospital during 1985-1988 (the "preperiod"), 1988-1997 (the "treatment period"), and 1997-2000 (the "post period"). All dependent variables are censored at the $5^{\text {th }}$ and $95^{\text {th }}$ percentiles. I also construct two indicators of financial distress using the 1988 HCRIS data: the share of patients covered by Medicaid, and the aggregate debt: asset ratio. Prior research suggests that financiallydistressed hospitals are more likely to be party to a merger or acquisition. I obtain

constructed with the guidance of HCRIS experts at CMS. Records with discount factors outside of $[0,1]$ or negative values for any measure in the price formula are excluded.

${ }^{17}$ Keeler et al. use a two-step process to adjust for each hospital's case-mix. First, they use California discharge data for 10 common diagnoses to run 10 separate regressions of net inpatient revenue per diem on patient characteristics and hospital dummies. Next, they use the 10 coefficients for each hospital to construct a weighted average price index.

${ }^{18}$ CMS uses the distribution of a hospital's Medicare admissions across roughly 500 Diagnosis-Related Groups, or DRGs, to construct that hospital's annual CMI. Each DRG is associated with a weight. The CMI is the admissions-weighted average DRG weight for the hospital. The weights were originally constructed (in 1984) so that the average CMI across all hospitals would equal 1; this average has since crept higher.

${ }^{20}$ Between 1985 and 2000 , the $5^{\text {th }}$ percentile of the annual price distribution ranges from $\$ 1374$ to $\$ 1664$ (in $\$ 2000$ ), and the $95^{\text {th }}$ percentile from $\$ 6256$ to $\$ 8334$. 
market-level control variables such as county per-capita income in 1990 from the Area Resource File. Estimates of county-level HMO penetration in 1994 were provided by Laurence Baker. $^{21}$

Latitude and longitude coordinates for the main address reported by each hospital in the 1988 AHA survey were purchased from geocode.com. Using these coordinates, which contain 6 decimal places and are accurate up to the street segment, I calculate the straight-line distance between hospitals ("as the crow flies"). After identifying 213 hospitals located within 0.3 miles of another, I performed a secondary check by examining individual maps of these pairs from Mapquest.com. Restricting the definition to exclude hospitals located more than 5 blocks apart reduces the final number of colocated hospitals to 191. In section 6, I illustrate the robustness of the results to alternative colocation definitions. $^{22}$

The first column in Table 1 presents descriptive statistics for the "All Hospitals" sample, which includes hospitals with nonmissing data for all independent variables (4,487 out of 4,907 hospitals, accounting for 91 percent of 1988 discharges). Within this sample, 178 (4 percent) were party to an independent merger between 1989 and 1996, and 163 (3.6 percent) were co-located with at least one hospital. ${ }^{23} 18$ of the 163 subsequently merged, yielding a merger rate of 11 percent in the co-located subset. ${ }^{24}$

\footnotetext{
${ }^{21}$ These estimates were constructed using data from the Group Health Association of America.

${ }^{22}$ For the purposes of identifying co-located hospitals and counting rivals, all general, non-federal hospitals with valid addresses in the non-territorial U.S. are included; sample restrictions are applied after this step is complete.

${ }^{23}$ A total of 194 hospitals were involved in the 97 independent mergers between 1989 and 1996. Of these hospitals, 192 are included in the 1988 AHA data, which is the starting point for the analysis. All 192 are present when rival merger counts and colocation variables are constructed. However, the "All Hospitals" sample excludes 13 of the 192 due to missing covariates, and 1 because it is located in a rural area. As
} 
The "Rivals Sample" (Column 2) is limited to non-merging hospitals in the All Hospitals sample that have two or more rivals within 7 miles in 1988, and nonmissing price data during the pre-period and the treatment period. The rationale for the $2+$ rival requirement is straightforward: if a nonmerging hospital has fewer than 2 rivals, it cannot experience a rival merger and thus should not be included in the sample. The rationale for the 7-mile cutoff is that the merger of adjacent hospitals can reasonably be expected to affect the prices of rivals located within fairly tight geographic bounds. In Section 6, I examine the sensitivity of the results to alternative market definitions. Given the sample restrictions, hospitals in the Rivals Sample are generally located in densely-populated urban areas. As compared to the All Hospitals sample, they are less likely to be government-owned (10 vs. 26 percent), and more likely to offer teaching programs (16 vs. 6 percent).

The Rivals Sample can be subdivided into hospitals with merging rivals (NMW hospitals, $\mathrm{N}=118$, column 3), and hospitals without merging rivals (NMWO hospitals, $\mathrm{N}=759$, column 4). NMW and NMWO hospitals share similar observable characteristics, although there are some statistically significant differences. NMW hospitals have a greater share of Medicaid patients, a larger number of rivals, and they operate in markets with slightly higher HMO penetration rates. They are also more likely to be very small $(<100$ beds). Price growth in the three years prior to the merger wave is significantly lower for NMW than for NMWO hospitals (-2.9 vs. 4.2 percent). This suggests that NMWO hospitals are inappropriate controls for NMW hospitals; that is, treating rival

noted in the text, rural hospitals are excluded because Dranove and Lindrooth did not seek to identify mergers in rural areas. The sole exception is due to a merger between a non-rural and a rural hospital. ${ }^{24}$ All 10 mergers involving colocated hospitals are represented among these 18 hospitals ( 2 of the 20 hospitals involved in the mergers are missing for reasons given in the preceding footnote). 
mergers as exogenous will produce underestimates of the impact of rival merger on price. This conjecture is corroborated in the OLS results presented below.

\section{$5 \quad$ Empirical Analysis}

To estimate the price effects of merger, I focus on the prices charged by rivals of merging hospitals. If merging hospitals raise price, and prices are strategic complements, rivals of these hospitals should be able to raise price as well. This approach allows me to eliminate merging hospitals from the primary analysis, which is ideal as they differ from nonmerging hospitals in unobservable ways that are likely to be correlated with price changes. However, selection issues persist even in the sample of nonmerging hospitals, as nonmerging hospitals in markets with mergers (NMW hospitals) are likely to be different in relevant, unobserved ways from nonmerging hospitals in markets without mergers (NMWO hospitals). Thus, I introduce an instrument for exposure to a rival merger, namely the number of co-located rival hospital pairs. If this measure is correlated with the propensity for rivals to merge, and otherwise uncorrelated with price growth of area hospitals, it is a valid instrument for rival merger and can be used to produce unbiased estimates of the price effect of rival merger.

I proceed in two steps. First, I validate the conjecture that co-located hospitals are more likely to merge. For this analysis, I use the All Hospitals sample. Second, I use the Rivals Sample to obtain an instrumental variables estimate of the effect of rival merger 
on price. ${ }^{25}$ I compare this estimate with the estimate from an OLS regression that takes rival merger to be exogenous.

\subsection{Co-location and the Probability of Merger}

Using the raw data from the All Hospitals sample, co-location performs quite well as a predictor of merger: the merger rate for co-located hospitals is 11.0 percent, as compared to 3.7 percent for non-co-located hospitals. Table 2 presents the results of a linear probability model that includes all of the hospital characteristics reported in Table 1, as well as market characteristics such as the county-level HMO penetration rate, per-capita income, and total population. To control for the possibility that state regulatory boards affect the merger rate, results are also presented with state fixed effects.

The relationship between the probability of merger and co-location is robust to all of the controls: co-location is associated with an increase of 6-7 percentage points in the probability of merger. As a falsification exercise, I reestimate these models using an indicator for system merger as the dependent variable. System mergers are defined by Dranove and Lindrooth as one-to-one consolidations of hospitals that did not surrender a facility license and report joint data following the consolidation. The coefficient estimates from these regressions are small and statistically insignificant. ${ }^{26}$ As expected, co-location is a good predictor of fully-integrated mergers but not of all merger and acquisition-related activity. Hence, the point estimates pertain only to these particular types of mergers.

\footnotetext{
${ }^{25}$ An alternative approach would be to use own co-location as an instrument for own merger. The advantage of rival analysis is that it potentially exploits each merger several times (when multiple hospitals are exposed to the same merger), increasing the sample size substantially.

${ }^{26}$ The point estimates are $-.020(.011)$ with or without state fixed effects.
} 
Given the strong relationship between co-location and merger, the relationship between rival co-location and rival merger in the rivals sample should also be strong. Table 2, column 3 reports the results of a linear regression of the number of rival mergers on the number of co-located rival pairs, again controlling for hospital and market characteristics. Column 4 adds state fixed effects. These specifications reveal that having one additional pair of co-located rivals is associated with an increase of roughly 0.11 in the number of rival mergers, as compared to a mean of 0.16 . This regression constitutes the first stage in the two-stage least squares rival analysis.

For rival co-location to be a good instrument for rival merger, it must also be uncorrelated with unobserved factors related to price growth. ${ }^{27}$ To examine whether this condition is satisfied, I regress price growth during the pre-period on the number of colocated rival pairs and the controls listed above. ${ }^{28}$ The results, reported in columns 1 and 2 of Table 3, reveal a negative and statistically insignificant relationship between the number of co-located rival pairs and price growth. Thus, there is no empirical evidence suggesting that price growth before the merger wave was greater for hospitals with colocated rivals.

\footnotetext{
${ }^{27}$ This assumption would be violated if, for example, prior to1988 new hospitals were likelier to enter adjacent to existing hospitals in areas where prices were expected to increase during 1988-96. In that case, price growth for hospitals with colocated rivals would be faster for reasons unrelated to the greater propensity for these rivals to merge As there has been very little entry in the acute-care hospital industry since the Hospital Survey and Construction Act of 1946 (known as Hill-Burton), this seems a reasonable assumption. Exit was not uncommon, however less than one percent of the hospitals in the study sample have rivals who exited during the study period. All results are robust to including a control for the number of exiting rivals.

${ }^{28}$ Regressions for pre-period price growth use hospital covariates from 1985. Regressions for the treatment period use covariates from 1988, and regressions for the post-period use covariates from 1997.
} 


\subsection{The Impact of Merger on Rivals' Prices}

The reduced form of the rival analysis is a regression of price growth during the treatment period on the number of co-located rival pairs and all of the control variables. Price growth is measured as the change in logged price between 1988, the year before the first merger in the dataset, and 1997, the year following the last merger in the dataset. Results from the reduced form are reported in columns 3 and 4 of Table 3. Each additional pair of co-located rivals is associated with a statistically-significant increase of 0.045 in price growth, as compared to a mean of 0.010 during this period. The estimate falls slightly to 0.034 and remains statistically significant upon inclusion of state fixed effects. Columns 5 and 6 report results using price growth in the post period, 1997-2000, as the dependent variable. As in the pre-period, there is no relationship between price growth and the number of co-located rivals.

Table 4 presents the IV estimate of the effect of a rival's merger between 1989 and 1996 on price growth between 1988 and 1997. The point estimate is simply the ratio of the reduced-form and first-stage coefficient estimates, $0.045 / 0.119 \approx 0.376$, with a standard error of $0.132 .{ }^{29}$ This figure translates into a cumulative price increase of approximately 46 percent ( 35 percent using the model with state fixed effects). ${ }^{30}$ This is equivalent to moving a hospital from the $25^{\text {th }}$ to the $65^{\text {th }}$ percentile of price growth during this period, or the $75^{\text {th }}$ to the $95^{\text {th }}$ percentile. (Real price growth in the rivals sample

\footnotetext{
${ }^{29}$ When using the exact (unrounded) coefficients, this ratio is identical to the IV estimate because there is a single endogenous regressor and the model is exactly identified.

${ }^{30} \mathrm{e}^{0.376} \approx 1.46$ and $\mathrm{e}^{0.301} \approx 1.35$
} 
averaged 1 percent between 1988 and 1997, with a standard deviation of 33 percent.) $)^{31}$

Given there is no relationship between co-located rival pairs and price growth during the post-merger period, these mergers appear to have induced a large one-time price increase or short-term boost in the pace of price growth rather than a transition to a permanently steeper price trajectory.

Table 4 also reports OLS estimates of the effect of rival merger on price growth. As in Connor and Feldman (1998), I too find no statistically significant impact of a rival's merger on price using OLS. Hausman specification tests easily reject equality of the two estimates for models with and without state fixed effects.

\section{Extensions and Robustness}

\subsection{Alternative Explanations}

The identification strategy assumes that, controlling for observable characteristics, any systematic difference in the price growth exhibited by nonmerging hospitals in markets with co-located rivals and nonmerging hospitals in markets without co-located rivals is due to the greater frequency of rival mergers to which the former group is exposed. The finding that price growth is similar for both groups prior to the start of the merger wave provides some support for this assumption; however, the study period is

\footnotetext{
${ }^{31}$ These estimates are similar in magnitude to the price increases implemented by Evanston Northwestern Healthcare (ENH) following its 1999 acquisition of nearby (but not co-located) Highland Park Hospital. ENH did not dispute the price increases alleged in the FTC complaint. These include increases of $52 \%$ at the Evanston facility for UnitedHealthcare's HMO, 190\% for UnitedHealthcare's PPO, $60 \%$ for Humana, $40 \%$ for Private Healthcare Systems, and 15-20\% for Aetna and Cigna's HMOs (Modern Healthcare, $1 / 2 / 2006)$. Note these figures represent increases by merging hospitals rather than their rivals. Increases by merging hospitals may be higher or lower than increases by rivals. As demonstrated by Gal-Or (1999), Capps, Dranove, and Satterthwaite (2005), and Ho (2007), the average negotiated post-merger price for any given hospital depends on its relative bargaining power vis-a-vis insurers in the post-merger marketplace.
} 
long and it is possible that omitted factors affect the evolution of prices in these markets differently during this particular period.

The most important such factor is the strength of managed care. Although I control for the percent of the population enrolled in managed care in each market, the negotiating power of these organizations varies widely. As a result, it is helpful to use the model from Section 2 to generate predictions regarding how changes in demand would affect prices in the two market types. In the context of this model, the growth of managed care is similar to a reduction in $v$, buyers' maximum willingness-to-pay for hospital services. The impact of a decline in $v$ on equilibrium price (i.e. $\mathrm{dP} * / \mathrm{d} v$ ) depends on the value of the transport cost $t$, but for the relevant range of $t$, price is as sensitive or more sensitive to $v$ markets with co-located rivals. The intuition for this result is that prices in more competitive markets are more sensitive to changes in costs or demand because firms are less able to absorb such shocks by cutting into their profit margins. Thus, if anything we might expect lower price growth in markets with co-located rivals, strengthening the argument that the higher observed growth is due not to the structural propensity for hospitals in such markets to raise prices particularly rapidly but rather to the increased frequency of mergers induced by colocation.

Another empirical test of the identifying assumption is to see whether the results are robust to the exclusion of all control variables. Assuming that the correlation between observable factors and the instrument is similar to that between unobservable factors and the instrument, a robust result suggests the estimates are not biased by 
unobserved factors. Indeed, the estimated merger effect, presented in column 2 of Appendix Table 1, is virtually unchanged when all controls are omitted.

\subsection{Specification Checks}

Table 5 explores the sensitivity of the results to alternative definitions for colocation and changes in market boundaries. IV estimates without state fixed effects are reported for all combinations of these definitions and boundaries. ${ }^{32}$ The results are fairly insensitive to the co-location definition, with statistically-significant point estimates ranging between 0.326 and 0.511 . The Mapquest corrections eliminate a small amount of noise in the co-location measure, but this noise does not appear to be systematic. In the (unreported) first-stage regression using 0.3 miles as the co-location definition (i.e. eliminating the 5-block Mapquest restriction), the coefficient on co-located rival pairs is 0.117 (.017), as compared to $0.119(.018)$ for the Mapquest-corrected version (reported in Table 2).

The alternative definitions for co-location can also be used to perform an overidentification test of the co-location instrument. The model can be estimated by 2SLS using two instruments for rival merger: the number of rival pairs less than .2 miles apart, and the number of rival pairs .2 to .3 miles apart. Regressing the residuals from this model on all instruments (which includes the exogenous regressors) and multiplying the resulting R-squared by $\mathrm{N}$ produces a test statistic that is distributed as a chi-squared statistic with one degree of freedom (Hausman 1983). The test statistic of .36 (p-

\footnotetext{
${ }^{32}$ Results with state fixed effects are similar and available upon request.
} 
value $=.55$ ) supports the null hypothesis of exogeneity of the instruments. I obtain similar results using $0-.2$ and $.2-.4$ as the co-location ranges.

To expand the instrument set, I also considered a variant of the co-location instrument: the number of co-located rival pairs of the same ownership type (i.e. both NFP hospitals, both FP hospitals, and both government hospitals). Ceteris paribus, hospitals of the same ownership type may be more likely to merge due to common objectives and financial arrangements. Including these additional instruments had virtually no effect on the results as there were too few non-zero values. Other variants that may be correlated with the propensity for co-located hospitals to merge, such as the overlap of particular service offerings, are not time-invariant and may not be exogenous to contemporaneous market conditions. ${ }^{33}$

In the main analysis, the market for a given hospital is defined to include all rivals within 7 miles. The number of rival mergers and co-located rival pairs within this circular boundary are then counted. Theoretically, the effect of rival merger should be stronger for closer rivals, and weaker for rivals located further away. Indeed, the point estimates more than double when the market radius is set at 5 miles, while the price effect is small and statistically insignificant when all rivals within 10 miles are included. ${ }^{34}$

Appendix 2 presents results from a series of alternative specifications, including a model with a negative binomial regression in the first stage, and a model with changes in price levels (rather than logs) as the dependent variable. The uniformity of the estimates

\footnotetext{
${ }^{33}$ A small number of hospitals did undergo ownership conversions during the study period, but for the vast majority ownership status is time-invariant (as is location).

${ }^{34}$ Note that reducing the market size also reduces the number of observations, as there are fewer hospitals with $2+$ rivals within a shorter distance.
} 
across the various specifications confirms the initial results: mergers between independent, close rivals lead to dramatic increases in market prices for inpatient care.

\section{Conclusions}

Observational studies of merger effects are plagued by severe selection bias. To overcome this bias, I propose a combination of rival analysis with instrumental variables. This approach uses the responses of rivals to gauge the anticompetitive effects of mergers, instrumenting for whether a rival is exposed to a merger in the first place. Using data on mergers in the hospital industry between 1989 and 1996, I find that hospitals increase price substantially following the merger of rivals within 7 miles. The point estimate of approximately 40 percent is consistent with predictions from structural models of hospital choice. ${ }^{35}$

For these mergers to have increased consumer welfare, they would have had to generate enormous quality improvements. Only one prior study has explored the effect of hospital mergers on quality, and this study finds evidence of slight reductions in quality (Hamilton and Ho 2000). On the other hand, producer welfare appears to have increased substantially, both as a result of price gains (paired with inelastic demand) and potentially large cost reductions (Dranove and Lindrooth 2003). Caution must be exercised, however, when extrapolating these conclusions to hospital mergers in general.

\footnotetext{
${ }^{35}$ Using hospital discharge data from California, Capps et al. (2003) and Gaynor and Vogt (2003) predict price increases of 10 to 58 percent for hypothetical mergers in markets with few competitors. These estimates are likely to be downward-biased, as the models assume that rivals do not react to the price increases of the merged institution. If prices are strategic complements, the newly-merged entity will raise prices more because it anticipates the reaction of its rivals.
} 
The estimates I obtain rely on responses to mergers of co-located hospitals, which enjoy especially strong post-merger increases in market power.

There are four key implications of the findings. First, comparing price growth of merging firms with price growth of non-merging rivals is likely to yield substantial underestimates of merger effects in differentiated oligopoly settings. Second, when selection bias is addressed, there is conclusive evidence that mergers of independent hospitals can lead to large increases in area prices, a result that has not emerged from prior longitudinal studies. Third, the magnitudes of these increases are consistent with predictions generated from structural models of similar settings (Capps, Dranove and Satterthwaite (2003) and Gaynor and Vogt (2003)). Although these models have mainly been used to predict price increases of merging firms themselves, the large estimated effects (in concentrated markets) suggest rivals of these firms could sustain significant price increases. Therefore, the results in this paper validate the use of careful structural modeling to estimate the impact of proposed mergers. Fourth, the analysis reveals that most geographic definitions of hospital markets are too large for urban areas. Fixedradius definitions of 5 to 7 miles appear to be more appropriate than the commonly-used 15 to 20 miles (and by extension, counties or MSAs).

The methodology in this study could be applied to a number of industries that have also experienced merger waves, ranging from independent video stores to retail banks. Various permutations of distance between firms or outlets - whether in product or physical space - could serve as instruments for merger, assuming they meet the requirement of exogeneity. More generally, research that carefully addresses the 
endogeneity of merger events or models the appropriate counterfactual outcome in the absence of merger is needed in order to achieve a greater understanding of the effects of consolidations in various settings. 


\section{References}

Alexander, J.A., M.T. Halpern, and S.D. Lee (1996), "The Short-Term Effects of Merger on Hospital Operations," Health Services Research, 30(6): 827-847.

Bazzoli, Gloria J., Anthony LoSasso, Richard Arnould, and Madeleine Shalowitz (2002), "Hospital Reorganization and Restructuring Achieved Through Merger," Health Care Management Review, 27(1): 7-20.

Capps, Cory, David Dranove, and Mark Satterthwaite (2003) "Competition and Market Power in Option Demand Markets," Rand Journal of Economics, 34(4): 737-763.

Chevalier, Judith (1995), "Capital Structure and Product Market Competition: Empirical Evidence from the Supermarket Industry," American Economic Review, June 1995.

Connor, Robert, Roger Feldman, and Bryan Dowd (1998) "The Effects of Market Concentration and Horizontal Mergers on Hospital Costs and Prices," International Journal of the Economics of Business, 5(2): 159-80.

Connor, Robert and Roger Feldman (1998) "The Effects of Horizontal Hospital Mergers on Nonmerging Hospitals," Managed Care and Changing Health Care Markets, (Michael A. Morrisey, ed.), Washington, DC: The AEI Press.

Cuellar, Alison E. and Paul J. Gertler (2003), "Trends in Hospital Consolidation," Health Affairs, 22(6): 77-87.

Dafny, Leemore (2005), "How Do Hospitals Respond to Price Changes?" American Economic Review, December, 95(5): 1525-1547.

Dranove, David and Richard Lindrooth (2003), "Hospital Consolidation and Costs: Another Look at the Evidence," Journal of Health Economics, 22: 983-997.

Dranove, David and William D. White (1994), "Recent Theory and Evidence on Competition in Hospital Markets," Journal of Economics and Management Strategy, 3(1): 169-209.

Eckbo, Espen (1983), "Horizontal Mergers, Collusion, and Stockholder Wealth,” Journal of Financial Economics, 11: 241-73.

Gal-Or, Esther (1999), "Mergers and Exclusionary Practices in Health Care Markets," Journal of Economics and Management Strategy, 8(3): 315-350. 
Gaynor, Martin and William B. Vogt (2000), "Antitrust and Competition in Health Care Markets," Handbook of Health Economics, (Anthony J. Culyer and Joseph P. Newhouse, eds.), Amsterdam: North-Holland.

Gaynor, Martin and William B. Vogt (2003), "Competition Among Hospitals," RAND Journal of Economics, 34(4): 764-785.

Hamilton, Barton and Vivian Ho (2000), "Hospital Mergers and Acquisitions: Does Market Consolidation Harm Patients?” Journal of Health Economics, 19: 767-791.

Hausman, Jerry (1983), "Specification and Estimation of Simultaneous Equations Models," in Z. Griliches and M. Intriligator, eds., Handbook of Econometrics, Amsterdam: North Holland.

Ho, Katherine (2007), "Insurer-Provider Networks in the Medical Care Market," NBER Working Paper 11822.

Keeler, Emmett B., Glenn Melnick, and Jack Zwanziger (1999), "The changing effects of competition on non-profit and for-profit hospital pricing behavior," Journal of Health Economics, 18(1): 69-86

Kaiser Family Foundation (2004), Employer Health Benefits Annual Survey, Menlo Park, CA.

Krishnan, Ranjani (2001), "Market Restructuring and Pricing in the Hospital Industry," Journal of Health Economics, 20: 213-237.

Salop, Steven (1979), "Monopolistic Competition with Experience Goods," Quarterly Journal of Economics, 101:265-279.

Spang, Heather, Gloria Bazzoli, and Richard Arnould (2001), "Hospital Mergers and Savings for Consumers: Exploring New Evidence," Health Affairs 20(4): 150-158.

Stigler, George (1964), “A Theory of Oligopoly,” Journal of Political Economy, 72, 4461.

Tay, Abigail (2003), "Assessing Competition in Hospital Care Markets: the Importance of Accounting for Quality Differentiation," RAND Journal of Economics, 34(4): 786-814.

Taylor, Mark (2006), "Behind the FTC's Lawsuit: Payers Pointed Finger at Evanston Northwestern," Modern Healthcare, January 2.

Town, Robert and William B. Vogt (2005), "Hospital Consolidation: What Impact on Prices and Quality?", mimeo. 
Vita, Michael G. and Laurence Schumann (1991), "The Competitive Effects of Horizontal Mergers in the Hospital Industry: A Closer Look," Journal of Health Economics 10: 359-372.

Wooldridge, Jeffrey M. (2002), Econometric Analysis of Cross Section and Panel Data, Cambridge, MA: The MIT Press.

Woolley, J. Michael (1989), "The Competitive Effects of Horizontal Mergers in the Hospital Industry,” Journal of Health Economics, 8: 271-91. 


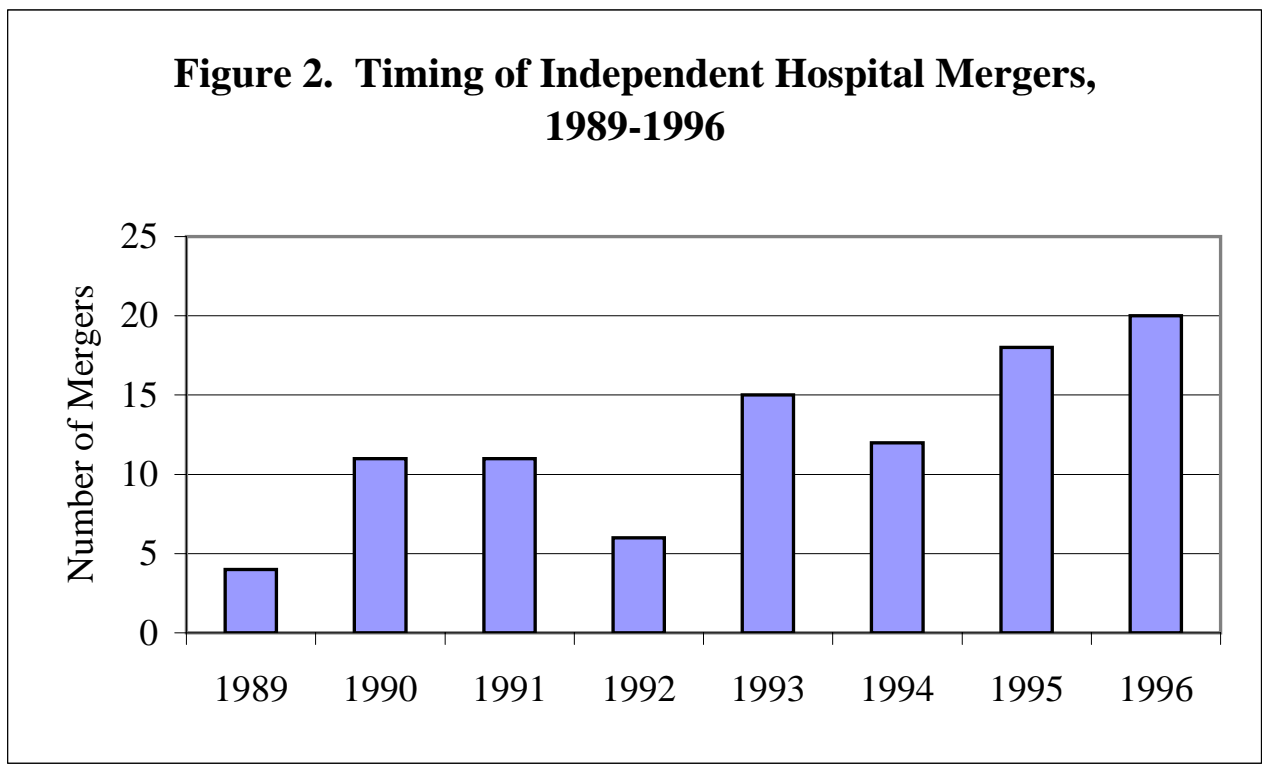

Source: Dranove and Lindrooth (2003) 
Table 1. Sample Means

\begin{tabular}{|c|c|c|c|c|}
\hline & All Hospitals & & Rivals Sample & \\
\hline & & AII & NMW & NMWO \\
\hline \multicolumn{5}{|l|}{ Dependent Variables } \\
\hline 1985 price & $\$ 3,223$ & $\$ 3,951$ & $\$ 3,935$ & $\$ 3,953$ \\
\hline 1988 price & $\$ 3,404$ & $\$ 4,057$ & $\$ 3,737$ & $\$ 4,107$ \\
\hline 1997 price & $\$ 3,851$ & $\$ 4,091$ & $\$ 3,823$ & $\$ 4,133$ \\
\hline 2000 price & $\$ 3,908$ & $\$ 4,067$ & $\$ 4,014$ & $\$ 4,075$ \\
\hline $\ln$ (1988 price)-ln(1985 price) & .064 & .032 & -.029 & .042 \\
\hline $\ln (1997$ price $)-\ln (1988$ price $)$ & .132 & .010 & .020 & .009 \\
\hline $\ln (2000$ price $)-\ln (1997$ price $)$ & .013 & .001 & .039 & -.005 \\
\hline \multicolumn{5}{|l|}{ Merger Indicators and Instruments } \\
\hline Merger & $4.0 \%$ & & & \\
\hline Co-located & $3.6 \%$ & & & \\
\hline No. of rival mergers & & .156 & 1.161 & 0 \\
\hline No. of co-located rival pairs & & .332 & .712 & .273 \\
\hline \multicolumn{5}{|l|}{ Hospital Characteristics } \\
\hline For-profit & $15.2 \%$ & $15.2 \%$ & $16.1 \%$ & $15.0 \%$ \\
\hline Government & $25.5 \%$ & $10.0 \%$ & $8.5 \%$ & $10.3 \%$ \\
\hline Teaching hospital & $6.4 \%$ & $16.3 \%$ & $18.6 \%$ & $15.9 \%$ \\
\hline Medicaid share of discharges & $11.4 \%$ & $11.2 \%$ & $15.1 \%$ & $10.6 \%$ \\
\hline Debt: asset ratio & $55.1 \%$ & $55.7 \%$ & $58.9 \%$ & $55.2 \%$ \\
\hline Occupancy rate & $56.5 \%$ & $66.3 \%$ & $67.7 \%$ & $66.1 \%$ \\
\hline \multicolumn{5}{|l|}{ Number of beds } \\
\hline $0-99$ & $41.0 \%$ & $5.4 \%$ & $10.2 \%$ & $4.6 \%$ \\
\hline 100-199 & $26.1 \%$ & $18.8 \%$ & $16.1 \%$ & $19.2 \%$ \\
\hline 200-299 & $14.7 \%$ & $26.1 \%$ & $25.4 \%$ & $26.2 \%$ \\
\hline 300-399 & $8.3 \%$ & $20.9 \%$ & $22.9 \%$ & $20.6 \%$ \\
\hline $400+$ & $9.9 \%$ & $28.8 \%$ & $25.4 \%$ & $29.4 \%$ \\
\hline \multicolumn{5}{|l|}{ Market Characteristics } \\
\hline No. of rivals within 7 miles & 3.16 & 7.37 & 12.03 & 6.64 \\
\hline \multicolumn{5}{|l|}{ MSA Population } \\
\hline Not in MSA & $44.0 \%$ & $3.0 \%$ & $0.8 \%$ & $3.3 \%$ \\
\hline$<250,000$ & $10.7 \%$ & $9.9 \%$ & $6.8 \%$ & $10.4 \%$ \\
\hline 250,000-499,999 & $9.4 \%$ & $17.6 \%$ & $16.9 \%$ & $17.7 \%$ \\
\hline $500,000-1,000,000$ & $10.7 \%$ & $19.2 \%$ & $20.3 \%$ & $19.0 \%$ \\
\hline $1,000,000-2,500,000$ & $13.8 \%$ & $27.4 \%$ & $25.4 \%$ & $27.7 \%$ \\
\hline$>2,500,000$ & $11.4 \%$ & $23.0 \%$ & $29.7 \%$ & $22.0 \%$ \\
\hline County HMO penetration & $14.5 \%$ & $21.3 \%$ & $23.7 \%$ & $20.9 \%$ \\
\hline County per-capita income & $\$ 17,154$ & $\$ 19,923$ & $\$ 20,036$ & $\$ 19,905$ \\
\hline$N^{*}$ & 4487 & 877 & 118 & 759 \\
\hline
\end{tabular}

Notes: Prices are inflated to year 2000 dollars using the CPI-U. Price change variables are censored at the 95th and 5th percentiles. Hospital and market characteristics are measured as of 1988, with the exception of county HMO penetration, which is for 1994. Rivals are defined as hospitals located within a 7-mile radius.

*In column 1, N for the price data is: 3,802 (1985), 4,026 (1988), 3,462 (1997), and 3,240 (2000). All hospitals in the Rivals Sample have price data for 1985, 1988, and 1997. 2000 data is available for 99 of the NMW hospitals and 672 of the NMWO hospitals.

Sources: Medicare Cost Reports, Prospective Payment Impact Files, Dranove and Lindrooth (2003), geocode.com, American Hospital Association, Area Resource File, author's calculations 
Table 2. Relationship Between Merger/Rival Merger and Co-location/Rival Co-location (First Stage)

\begin{tabular}{|c|c|c|c|c|}
\hline \multirow{4}{*}{ Co-located } & \multicolumn{2}{|c|}{ Own Merger } & \multicolumn{2}{|c|}{ Number of Rival Mergers } \\
\hline & (1) & (2) & (3) & (4) \\
\hline & $.066 * * *$ & $.062 * * *$ & & \\
\hline & $(.016)$ & $(.016)$ & & \\
\hline \multirow{2}{*}{ No. of co-located rival pairs } & & & $.119 * * *$ & $.112 * * *$ \\
\hline & & & $(.018)$ & $(.019)$ \\
\hline \multicolumn{5}{|l|}{ Hospital Characteristics } \\
\hline \multirow[t]{2}{*}{ For-profit } & -.005 & .003 & .071 & $.090 * *$ \\
\hline & $(.009)$ & $(.009)$ & $(.044)$ & $(.046)$ \\
\hline \multirow[t]{2}{*}{ Government } & $-.045 * * *$ & $-.037 * * *$ & -.067 & -.045 \\
\hline & $(.007)$ & $(.008)$ & $(.047)$ & $(.047)$ \\
\hline \multirow[t]{2}{*}{ Teaching hospital } & $.027 * *$ & .022 & -.008 & -.006 \\
\hline & $(.015)$ & $(.015)$ & $(.045)$ & $(.044)$ \\
\hline \multirow[t]{2}{*}{ Medicaid share } & .040 & .037 & $.399 * * *$ & $.321 * *$ \\
\hline & $(.031)$ & $(.032)$ & $(.130)$ & $(.130)$ \\
\hline \multirow[t]{2}{*}{ Debt: asset ratio } & -.009 & -.008 & -.006 & -.059 \\
\hline & $(.008)$ & $(.008)$ & $(.049)$ & $(.048)$ \\
\hline \multirow[t]{2}{*}{ Occupancy rate } & .012 & -.004 & .189 & -.125 \\
\hline & $(.020)$ & $(.021)$ & $(.120)$ & $(.126)$ \\
\hline \multicolumn{5}{|l|}{ Number of beds } \\
\hline \multirow[t]{2}{*}{ 100-199 } & .009 & .013 & $-.156 * *$ & $-.118 *$ \\
\hline & $(.008)$ & $(.008)$ & $(.067)$ & $(.064)$ \\
\hline \multirow[t]{2}{*}{$200-299$} & $.019 *$ & $.023 * *$ & $-.153^{* *}$ & $-.129 * *$ \\
\hline & $(.010)$ & $(.010)$ & $(.067)$ & $(.064)$ \\
\hline \multirow[t]{2}{*}{ 300-399 } & -.018 & -.010 & $-.153 * *$ & -.089 \\
\hline & $(.013)$ & (.013) & $(.070)$ & $(.067)$ \\
\hline \multirow[t]{2}{*}{$400+$} & -.019 & -.009 & $-.184 * *$ & $-.127 *$ \\
\hline & $(.014)$ & $(.014)$ & $(.072)$ & $(.069)$ \\
\hline \multicolumn{5}{|l|}{ Market Characteristics } \\
\hline \multicolumn{5}{|l|}{ MSA Population } \\
\hline \multirow[t]{2}{*}{$<250,000$} & $.047 * * *$ & $.053 * * *$ & .047 & .110 \\
\hline & $(.011)$ & $(.011)$ & $(.092)$ & $(.092)$ \\
\hline \multirow[t]{2}{*}{$250,000-499,999$} & .000 & .004 & .055 & .101 \\
\hline & $(.012)$ & $(.012)$ & $(.087)$ & $(.087)$ \\
\hline \multirow[t]{2}{*}{$500,000-1,000,000$} & -.003 & .001 & .056 & .059 \\
\hline & $(.012)$ & $(.012)$ & $(.089)$ & $(.091)$ \\
\hline \multirow[t]{2}{*}{$1,000,000-2,500,000$} & $-.038 * * *$ & -.019 & -.030 & .021 \\
\hline & $(.012)$ & $(.013)$ & $(.090)$ & $(.092)$ \\
\hline \multirow[t]{2}{*}{$>2,500,000$} & $-.050 * * *$ & $-.035 * *$ & .056 & .141 \\
\hline & $(.014)$ & $(.015)$ & $(.093)$ & $(.096)$ \\
\hline \multirow[t]{2}{*}{ HMO penetration } & .037 & -.012 & $.464 * * *$ & $.379 *$ \\
\hline & $(.032)$ & .043 & $(.141)$ & $(.222)$ \\
\hline Ln(per-capita income) & $.070 * * *$ & $.046 * *$ & .002 & $-.277 * * *$ \\
\hline & $(.018)$ & $(.021)$ & $(.087)$ & $(.097)$ \\
\hline State fixed effects & $\mathrm{N}$ & $\mathrm{Y}$ & $\mathrm{N}$ & $\mathrm{Y}$ \\
\hline$N$ & 4487 & 4487 & 877 & 877 \\
\hline
\end{tabular}

Notes: All specifications are estimated by OLS. Models using own merger as the dependent variable are estimated on the All Hospitals Sample, while models using number of rival mergers as the dependent variable are estimated on the Rivals Sample.

$* * *$ signifies $\mathrm{p}<.01, * *$ signifies $\mathrm{p}<.05$, * signifies $\mathrm{p}<.10$ 
Table 3. Relationship Between Price Growth and Rival Co-location

(Reduced Form)

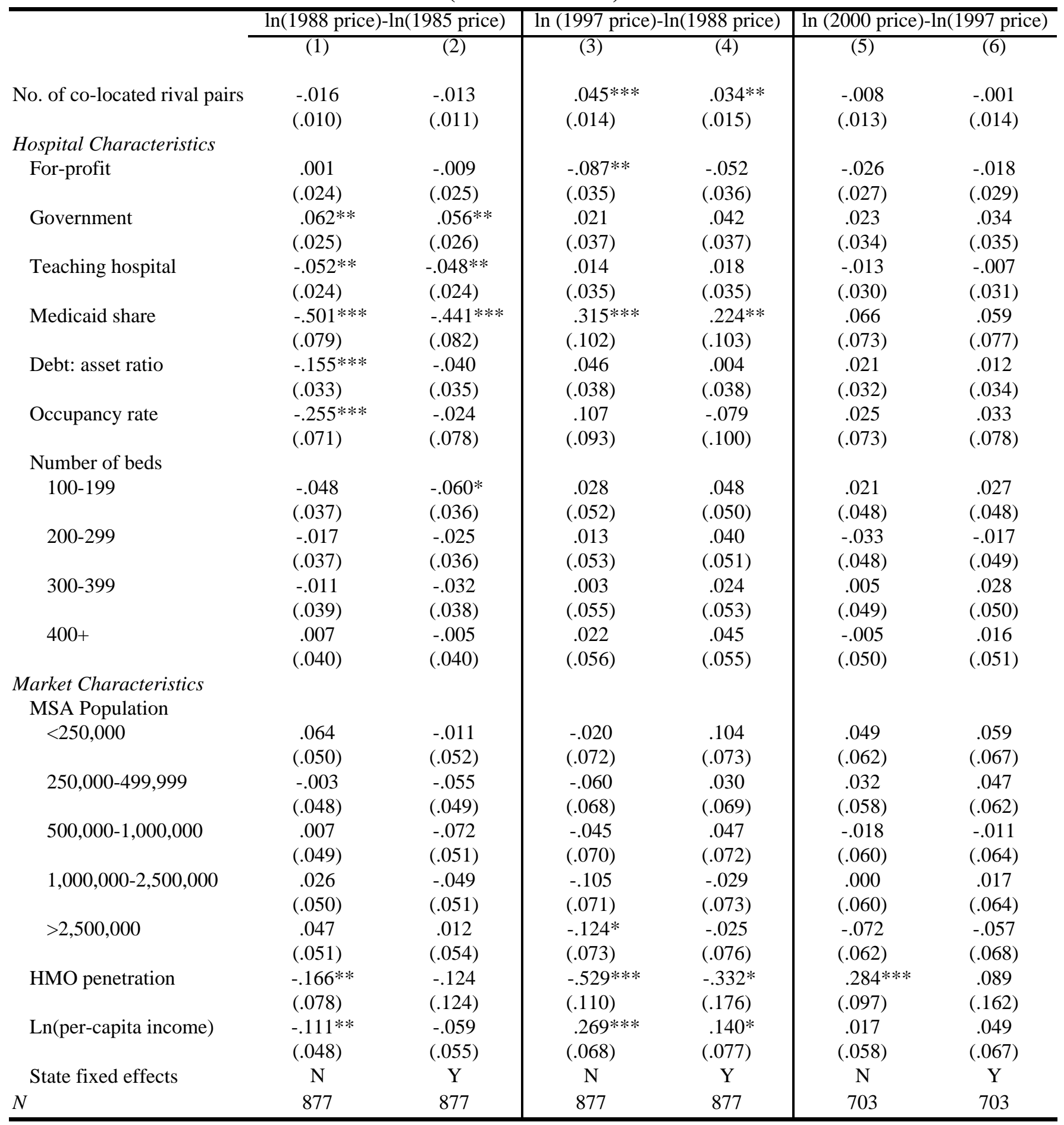

Notes: All specifications are estimated by OLS using the Rivals Sample.

$* * *$ signifies $\mathrm{p}<.01,{ }^{* *}$ signifies $\mathrm{p}<.05, *$ signifies $\mathrm{p}<.10$ 
Table 4. Effect of Rival Mergers on Price Growth

\begin{tabular}{lcc|cc}
\hline \multirow{2}{*}{ Estimation } & \multicolumn{4}{c}{$\ln (1997$ price) $-\ln (1988$ price $)$} \\
\cline { 2 - 5 } Number of rival mergers & $.376^{* * *}$ & $.301^{* *}$ & .016 & -.003 \\
& $(.132)$ & $(.147)$ & $(.026)$ & $(.027)$ \\
Hospital characteristics & $\mathrm{Y}$ & $\mathrm{Y}$ & $\mathrm{Y}$ & $\mathrm{Y}$ \\
Market characteristics & $\mathrm{Y}$ & $\mathrm{Y}$ & $\mathrm{Y}$ & $\mathrm{Y}$ \\
State fixed effects & $\mathrm{N}$ & $\mathrm{Y}$ & $\mathrm{N}$ & $\mathrm{Y}$ \\
$\mathrm{N}$ & 877 & 877 & 877 & 877 \\
\hline
\end{tabular}

${ }^{* * *}$ signifies $\mathrm{p}<.01, * *$ signifies $\mathrm{p}<.05, *$ signifies $\mathrm{p}<.10$ 
Table 5. Sensitivity of Results to Distance Cutoffs

\begin{tabular}{lcccc}
\hline & \multicolumn{4}{c}{ Co-location Definition } \\
\cline { 2 - 5 } Market Radius & \multicolumn{3}{c}{.3 miles and $<5$} \\
& .2 miles & .3 miles & blocks & .4 miles \\
\cline { 2 - 5 } 5 miles $(\mathrm{N}=722)$ & .992 & $.851^{* *}$ & $.962^{* * *}$ & $1.116^{*}$ \\
& $(.687)$ & $(.340)$ & $(.377)$ & $(.603)$ \\
7 miles $(\mathrm{N}=877)$ & $.511^{*}$ & $.326^{* * *}$ & $.376^{* * *}$ & $.431^{*}$ \\
& $(.298)$ & $(.125)$ & $(.132)$ & $(.221)$ \\
10 miles $(\mathrm{N}=1041)$ & .046 & .038 & .051 & .021 \\
& $(.082)$ & $(.050)$ & $(.054)$ & $(.072)$ \\
\hline
\end{tabular}

Notes: Each entry in the table is the IV estimate from a separate rival analysis. The entry in column 3, row 2 corresponds to the main specification that appears in column 1 of Table 4 ). $* * *$ signifies $\mathrm{p}<.01, * *$ signifies $\mathrm{p}<.05, *$ signifies $\mathrm{p}<.10$ 


\section{Appendix 1}

In this appendix, I derive the equilibrium price sets for the Salop circle models corresponding to market structures 1 and 2 in the text. I compare these prices to the prices that would arise following a merger between R1 and R2 (in each market structure).

\section{$\underline{\text { Market } 1}$}

Recall that co-located firms are undifferentiated and hence price at cost, which is zero. If $t$ is sufficiently low, $\mathrm{H}$ will set price to maximize

$$
\prod_{\mathrm{H}}=\mathrm{p}_{\mathrm{H}} \cdot \mathrm{D}\left(\mathrm{p}_{\mathrm{H}}, \mathrm{p}_{\mathrm{R} 1}=0, \mathrm{p}_{\mathrm{R} 2}=0\right)=\mathrm{p}_{\mathrm{H}} \cdot 2 \cdot\left(\frac{1}{4}-\frac{\mathrm{p}_{\mathrm{H}}}{2 \mathrm{t}}\right)
$$

H's demand (denoted D) consists of the individuals on either side (hence the multiple “2”) for whom transport costs to firms R1/R2 exceed $\mathrm{p}_{\mathrm{H}}$. The equilibrium price is $\mathrm{p}_{\mathrm{H}}^{*}=t / 4$.

If $t$ exceeds a threshold level, $\mathrm{H}$ will set price so that the marginal consumer earns zero surplus. If $t$ is extremely high, $\mathrm{H}$ is totally unconstrained by competition from $\mathrm{R} 1 / \mathrm{R} 2$ and prices as a local monopolist. In this case, the market will not be fully covered, i.e. not all consumers will purchase the product. (This range is unrealistic in this setting because hospital services generate a sufficiently high $v$ relative to $t$ to ensure fullycovered markets.) The full solution set is described by ${ }^{36}$

\footnotetext{
${ }^{36}$ This solution set may not appear intuitive at first blush. When $t$ is small, H's price increases in $t$ as the higher transport cost reduces competition with its rivals. Once $t$ is sufficiently large, $\mathrm{H}$ begins to compete
} 


$$
\mathrm{p}_{\mathrm{H}}^{*}= \begin{cases}t / 4, & t<8 v / 3 \\ 2 v-t / 2, & 8 v / 3<t<3 v \\ v / 2, & t>3 v .\end{cases}
$$

If R1 and R2 merge (into R), competition between them ceases, which relaxes the constraint on $\mathrm{H}$ substantially. For the lowest range of $t, \mathrm{H}$ now maximizes

$$
\prod_{H}=p_{H} \cdot D\left(p_{H}, p_{R}\right)=p_{H} \cdot 2 \cdot\left(\frac{1}{4}-\frac{p_{H}}{2 t}+\frac{p_{R}}{2 t}\right)
$$

By symmetry, $\mathrm{p}_{\mathrm{H}}^{*}=\mathrm{p}_{\mathrm{R}}^{*}$ and takes the following form

$$
\mathrm{p}_{\mathrm{H}}^{*}= \begin{cases}t / 2, & t<4 v / 3 \\ v-t / 4, & 4 v / 3<t<2 v \\ v / 2, & t>2 v .\end{cases}
$$

These solutions suggest that a merger of co-located rivals will result in a very sizeable price increase (up to 100 percent) so long as $\mathrm{H}$ actively competes with R1/R2 (i.e. the first two ranges for $t$ ).

with another option available to consumers: no purchase. The marginal consumer's reservation value is a binding constraint on H's price, yielding $\mathrm{p}_{\mathrm{H}}^{*}=\mathrm{v}-\mathrm{t} \bullet(1 / 2-\mathrm{v} / \mathrm{t})=\mathrm{t} / 2$. (Note the marginal consumer is located at $v / t$, as this is the point at which surplus from purchasing from R1/R2 equals zero.) Within this intermediate range of $t$, price decreases in $t$ in order to continue serving the marginal consumer. Finally, when $t$ is extremely high the firm acts as a local monopolist and is no longer constrained by $\mathrm{R} 1 / \mathrm{R} 2$. In this range, $t$ does not affect the tradeoffs at the margin and therefore does not enter into the monopolist's price. 


\section{Market 2}

The pre-merger $\mathrm{p}_{\mathrm{H}}^{*}$ (and $\mathrm{p}_{\mathrm{R} 1}^{*}$ and $\mathrm{p}_{\mathrm{R} 2}^{*}$, by symmetry) in market 2 is described by

$$
\mathrm{p}_{\mathrm{H}}^{*}= \begin{cases}t / 3, & t<2 v \\ v-t / 6, & 2 v<t<3 v \\ v / 2, & t>3 v\end{cases}
$$

Assuming that one of the $\mathrm{R}$ facilities closes post-merger and the other remains in the same location, post-merger $\mathrm{p}_{\mathrm{H}}^{*}$ is

$$
\mathrm{p}_{\mathrm{H}}^{*}= \begin{cases}t / 2, & t<6 v / 5 \\ v-t / 3, & 6 v / 5<t<3 v / 2 \\ v / 2, & t>3 v / 2\end{cases}
$$

These solutions illustrate why mergers among co-located hospitals are likely to be associated with particularly large price increases. In the realistic range of $t$ for each market (the range in which there is pre and post-merger competition among hospitals), the price increases in market 2 are much smaller on average than in market $1 .^{37}$

\footnotetext{
${ }^{37}$ When $v=1$, the average price increase for market 1 is 66.7 percent, and for market 2 it is 40 percent (the percentage increase varies with $t$ ).
} 


\section{Appendix 2}

The following table presents the coefficients of interest from several specification checks. All models are based on the main specification without state fixed effects. Column 1 repeats the main results as a reference point. Column 2 demonstrates that the results are similar when all hospital and market controls are excluded. Column 3 reveals that censoring of the dependent variable has only a slight effect on the point estimates. Column 4 adds controls for the number of rivals within a hospital's market. Because hospitals with more rivals are more likely to have co-located rivals as well as merging rivals, it is possible that the instrument is also capturing the effect of having more rivals. Theoretically, this could bias the estimate downward, as it would cause a larger firststage coefficient and a smaller reduced-form coefficient. Column 4 includes individual dummies for markets with $2,3, \ldots 9,10-15$, and $15+$ rivals. The result indicates a small downward bias, if any. Column 5 excludes hospitals that are co-located with other hospitals from the estimation sample (note the number of co-located rival pairs always excludes the pair to which a hospital belongs, if any). Column 6 uses the fitted values from a negative binomial first-stage regression as the instrument for the number of rival mergers (per Wooldridge 2002). Finally, Column 7 uses the change in price levels in place of the change in log prices as the dependent variable. The point estimate of $\$ 1566$ (in \$2000) is equivalent to 1.1 standard deviations of the distribution of price changes during this period, and corresponds to a movement from the $25^{\text {th }}$ to the $65^{\text {th }}$ or the $75^{\text {th }}$ to the $95^{\text {th }}$ percentiles in price (the same magnitude obtained using the original dependent variable). Yet another specification check (excluded here for lack of space) confirms that 
controlling for the number of rival hospital closures during 1988-97 does not affect the results.

\section{Appendix Table 1. Specification Checks}

\begin{tabular}{|c|c|c|c|c|c|c|c|}
\hline \multirow[t]{2}{*}{ Dependent variable } & \multicolumn{6}{|c|}{$\ln (1997$ price $)-\ln (1988$ price $)$} & \multirow{2}{*}{$\begin{array}{c}1997 \text { price- } \\
1988 \text { price } \\
(7)\end{array}$} \\
\hline & (1) & (2) & (3) & (4) & (5) & (6) & \\
\hline Number of rival mergers & $\begin{array}{l}.380 * * * \\
(.132)\end{array}$ & $\begin{array}{l}.352 * * * \\
(.132)\end{array}$ & $\begin{array}{l}.402 * * \\
(.143)\end{array}$ & $\begin{array}{l}.408^{* *} \\
(.198)\end{array}$ & $\begin{array}{l}.326^{* *} \\
(.122)\end{array}$ & $\begin{array}{l}.222 * * \\
(.099)\end{array}$ & $\begin{array}{l}1566^{* * *} \\
(563)\end{array}$ \\
\hline Hospital characteristics & $\mathrm{Y}$ & $\mathrm{N}$ & $\mathrm{Y}$ & Y & Y & Y & Y \\
\hline Market characteristics & $\mathrm{Y}$ & $\mathrm{N}$ & $\mathrm{Y}$ & Y & $\mathrm{Y}$ & Y & Y \\
\hline Censored dependent variable & $\mathrm{Y}$ & $\mathrm{Y}$ & $\mathrm{N}$ & Y & Y & Y & Y \\
\hline Number of rival dummies & $\mathrm{N}$ & $\mathrm{N}$ & $\mathrm{N}$ & Y & $\mathrm{N}$ & $\mathrm{N}$ & $\mathrm{N}$ \\
\hline Drop co-located hospitals & $\mathrm{N}$ & $\mathrm{N}$ & $\mathrm{N}$ & $\mathrm{N}$ & $\mathrm{Y}$ & $\mathrm{N}$ & $\mathrm{N}$ \\
\hline Use neg. binomial in first stage & $\mathrm{N}$ & $\mathrm{N}$ & $\mathrm{N}$ & $\mathrm{N}$ & $\mathrm{N}$ & Y & $\mathrm{N}$ \\
\hline $\mathrm{N}$ & 877 & 877 & 877 & 877 & 816 & 877 & 877 \\
\hline
\end{tabular}

Notes: All models are estimated by 2SLS. Prices are inflated to year 2000 dollars using the CPI-U.

$* * *$ signifies $\mathrm{p}<.01, * *$ signifies $\mathrm{p}<.05, *$ signifies $\mathrm{p}<.10$ 